\title{
Evaluation of selected insomnia predictors in adolescents and young adults with cystic fibrosis
}

\author{
Lucyna Tomaszek ${ }^{\mathrm{a}}$, Grazyna Cepuch ${ }^{\mathrm{b}}$, Lidia Pawlik
}

\begin{abstract}
Aims and Background. The purpose of the study was to assess the incidence of insomnia in adolescents and young adults with cystic fibrosis and its impact on the quality of life, and to examine whether demographic and clinical factors and negative emotional states are predictors of insomnia in these patients.

Methods. The study was conducted among 95 cystic fibrosis patients aged 14-25 years. The study used a personal questionnaire survey, the Athens Insomnia Scale, the Cystic Fibrosis Quality of Life Questionnaire, the Hospital Anxiety and Depression Scale, and the Numeric Rating Scale.

Results. Insomnia was diagnosed in $38 \%$ of cystic fibrosis patients. In patients with insomnia, the level of anxiety (Me: 10 vs. $4 ; P=0.000$ ) and depression (Me: 6.5 vs. $2 ; P=0.000$ ) was significantly higher than in the good sleep quality group. The risk of insomnia increases as anxiety (OR: $4.31 ; 95 \% \mathrm{Cl}: 2.20$ to 8.41 ) and depressive symptoms exacerbate (OR: $4.98 ; 95 \% \mathrm{Cl}: 1.84$ to 13.43$)$. Insomnia significantly worsens the quality of life in cystic fibrosis patients ( $B=-0.5, P=0.000$ ). Conclusion. Insomnia affects a large percentage of cystic fibrosis patients, and anxiety and depression are factors that increase the risk of insomnia. Insomnia decreases the quality of life in cystic fibrosis patients.
\end{abstract}

Key words: cystic fibrosis, insomnia, emotional state, pain, quality of life

Received: November 9, 2017; Accepted: March 14, 2018; Available online: March 21, 2018

https://doi.org/10.5507/bp.2018.009

${ }^{a}$ Department of Pneumonology and Cystic Fibrosis, Institute for Tuberculosis and Lung Diseases, Pediatric Division, Rabka-Zdroj, Poland ${ }^{b}$ Collegium Medicum, Faculty of Health Sciences, Jagiellonian University, Krakow, Poland

Corresponding author: Lucyna Tomaszek, e-mail: Itomaszek@igrabka.edu.pl

\section{INTRODUCTION}

Cystic fibrosis (CF) is an autosomal, recessive genetic disorder that is one of the most common among European, North American and Australian populations. It significantly shortens the survival time of patients. In Poland, it occurs in 1 per 4394 newborns ${ }^{1}$.

Over recent decades the patients' life has extended, mainly thanks to integrated, multidisciplinary care. Great expectations are associated with the implementation of innovative therapies (molecular therapy, gene therapy) that can provide a significant breakthrough in treatment ${ }^{2,3}$. Until the large-scale promising therapies are implemented, the effective modification of the course of the disease and the improvement of the lives of patients with CF are still determined by a reliable assessment of the physical and psycho-emotional status and the multidirectional standard therapy with its efficacy control. It is important to identify factors that may disturb the broadly defined functioning of the CF patient. Some of the recognized factors that destabilize the patient's well-being and directly or indirectly affect the life of an individual are sleep disorders, pain, and negative emotional states, such as anxiety and depression.

Scientific reports on sleep quality in patients with CF indicate the widespread prevalence of sleep disorders in this group of patients ${ }^{4}$, with simultaneous undesirable effects on many areas of physical and mental functioning ${ }^{5-8}$. Although factors that improve the quality of sleep and the condition of the body are being sought and implemented (e.g. including the role of melatonin)(ref. ${ }^{9}$ ), sleep disorders such as insomnia is still an important problem. Insomnia disorder is characterized by difficulty falling asleep, difficulty staying asleep or poor sleep quality, and it leads to impaired daytime functioning, tiredness, fatigue and sleepiness ${ }^{10}$. The lack of sleep or its improper architecture in CF patients leads, among others, to cognitive and behavioural deficits, which can reduce the ability to achieve goals and succeed in life. The analysis of scientific reports proves that the presence of sleep disorders not only affects the quality of life of CF patients, but also determines its expectancy ${ }^{11}$.

Also, the assessment of pain, anxiety and depression in a patient appears to be crucial because of their importance in inducing the "vicious circle" of mutual causal relationships with adverse effects on the patient. The appearance of the symptoms of anxiety or depression in this group of patients was the basis for prompt intervention and was followed by a suggestion of the proper treatment ${ }^{12,13}$. Measures aiming to diagnose anxiety and depression early are recommended to be implemented depending on the severity of symptoms. They should provide help starting from psychological support, through behavioural cognitive therapy, finishing with pharmacological treatment. The incidence of negative emotional states in patients with CF is unlikely to differ from that in the general population ${ }^{14-16}$; however, due to connotations with other variables negatively affecting health (e.g. respira- 
tory efficiency, pain) they are significant determinants of survival in CF patients ${ }^{17-19}$ and should be assessed on a regular basis. The pursuit of knowledge and understanding of the mutual relationships between variables, as well as the extension of research in this area can significantly improve the detection of negative factors and optimize the quality of medical care, with the consequent better emotional and physical condition of patients.

The purpose of the study was to: 1) assess the incidence of insomnia in adolescents and young adults with cystic fibrosis, 2) evaluate the relationship between insomnia and the quality of life, 3 ) investigate whether demographic and clinical factors and negative emotional states are predictors of insomnia in these patients.

\section{MATERIAL AND METHODS}

\section{Patient recruitment and assessment}

The study was conducted among 95 cystic fibrosis patients aged 14-25 who reported to the follow-up visit at the Institute of Tuberculosis and Lung Diseases in the Jan and Irena Rudnik Field Department in Rabka Zdrój. The study was carried out between February 2016 and February 2017 according to the ethical principles of the Helsinki Declaration, following the approval of the Bioethics Commission of the Jagiellonian University in Krakow (No.122.6120.275.2015).

The study involved patients who had agreed to participate voluntarily (the legal guardian's consent was also obtained for patients under 18 years of age). The study excluded patients after lung transplantation, those with diagnosed mental illness, in the terminal state, and with clinical worsening (aggravation of dyspnoea and cough, coughing up sputum, the use of assisted breathing or respirotherapy) in the 4 weeks prior to enrolment, or those who had had traumatic experiences in the last 6 months (e.g. relationship breakdown, death of a significant person, job loss).

The method of diagnostic survey with the questionnaire technique was used in the study, including Computer-Assisted Web Interview (CAWI) and the analysis of medical records.

In order to collect demographic data (age, gender) and basic information about the general state of patients' health (BMI, current analgesic treatment, comorbidities) a self-constructed questionnaire was used. Values of the basic breathing parameter of the last 4 weeks - FEV1 - were obtained from the patients' medical records. The severity of insomnia symptoms, quality of life, intensity of pain and emotional state (anxiety, depression) were assessed using standardized research tools.

\section{Assessment of insomnia}

The Polish version of AIS - Athens Insomnia Scale was used to assess insomnia ${ }^{20}$. The tool contains eight questions about various insomnia symptoms (range 0-24, higher scores indicating worse sleep). The first five positions allow for the identification of such symptoms of sleep disorders as difficulty in falling asleep, waking up at night, waking up early in the morning, duration, and the quality of sleep. The other three questions concern daily functioning, and assess well-being, physical and psychological efficiency, as well as the feeling of drowsiness. The symptoms are scored on a scale of 0-3 pts (where 0 means the absence of any symptom and 3 - severe intensity of symptoms) only if they occurred at least three times a week during the last month. Obtaining a minimum of $8 / 24$ pts for a patient means the likelihood of insomnia. The AIS can be used - both in clinical practice and research - as a tool for measuring the severity of sleep problems and as a screening tool for diagnosing insomnia in adolescents and adults ${ }^{20-22}$.

\section{The evaluation of the progression of bronchial-pulmonary disorders}

The degree of the patient's respiratory failure was determined based on the analysis of forced expiratory volume at one second (FEV1). FEV1 $>70 \%$ indicated the early stage of the disease, FEV $1<70 \%$ and $>40 \%$ medium, and FEV1 $<40 \%$ advanced $^{23}$.

\section{The evaluation of quality of life}

Quality of life was assessed using a questionnaire survey, CFQoL (Cystic Fibrosis Quality of Life), adapted to Polish conditions 24. It contains 52 questions (scored on a scale of 1-6), divided into 9 subscales: physical functioning, social functioning, treatment issues, chest symptoms, emotional functioning, future concerns, relationships, body image, career concerns. Global quality of life will be estimated for the purpose of this work (range: $0-100$ pts, 0 - worst quality of life, 100 - best quality of life).

\section{Pain assessment}

The Numeric Rating Scale (NRS) was used to evaluate the intensity of pain ${ }^{25}$ and the efficacy of the analgesic used by the patient, where 0 meant no pain/the lack of analgesic efficacy, and 10 - the most severe pain/maximum efficacy of analgesia.

\section{The evaluation of anxiety and depression}

The Hospital Anxiety and Depression Scale - HADS (ref. ${ }^{26}$ ) adapted to Polish conditions ${ }^{27}$ was used to assess anxiety and depressive symptoms. The scale consists of 7 items in the subscales: anxiety and depression. For every item, the respondent chooses one of the four answers that best describes his/her physical and mental state in the last week. Answers are coded on a 0-3 point scale. Cut-off scores are provided, discriminating normal (0-7 pts), borderline (8-10 pts) and clinical levels of symptoms $(\geq 11$ pts). HADS is a useful screening tool for identifying people with emotional disorders ${ }^{28}$.

\section{Statistical analysis}

Statistical analysis was performed using the Statistica 12 software, including a medical kit (StatSoft ${ }^{\circledR}$, Poland). Qualitative variables are expressed by number and percentage. Quantitative variables are expressed by mean and standard deviation (normal distribution) or median, 
upper and lower quartile (distribution deviating from normal). The normality of the distribution of variables was verified by the W Shapiro-Wilk test. Differences between the two independent groups were assessed using the t-student or Mann-Whitney U test. Intergroup differences between qualitative variables were evaluated with chi $^{2}$ and Fisher's exact tests. Correlations between numerical parameter values were determined on the basis of Spearman's ( $R$ ) rank correlation coefficient. The relationship between multiple independent variables and the quantitative dependent variable was studied by means of stepwise progressive regression. The logistic regression model was used to describe the influence of quantitative variables on the dichotomic variable. The level of statistical significance was assumed at $P=0.05$.

\section{RESULTS}

The statistical analysis covered data obtained from 95 patients with $\mathrm{CF}$, divided into 2 groups depending on the quality of sleep. The first group were patients with good sleep quality (AIS <8 pts; $n=59 ; 62.1 \%$ ), the second patients suffering from insomnia (AIS $\geq 8$ pts; $n=36 ; 37.9 \%$ ).

The groups did not differ significantly in terms of age, sex, BMI, FEV1 scores, and the number of comorbidities (Table 1). 51.6\% $(n=49)$ of patients suffered solely from the primary disease. In the remaining patients, $\mathrm{CF}$ was accompanied by one and more other illnesses resulting from the nature of the disease.

\section{Prevalence of insomnia}

About $40.0 \%(n=36)$ of the subjects received 8 or more AIS scores, suggesting the presence of insomnia.

The percentage of people suffering from insomnia was similar among men and women (46.3\% vs. $31.5 \%$; $\left.\chi^{2}=2.186 ; P=0.139\right)$ and in the age groups: $14-16$ years vs. $17-20$ years vs. $21-25$ years ( $24 \%$ vs. 42.8 vs. $42.8 \%$; $\left.\chi^{2}=2.783 ; P=0.248\right)$.

\section{The evaluation of the relationship between insomnia and the quality of life}

Insomnia is a factor that significant deteriorates the quality of life in patients with $\mathrm{CF}(\beta=-0.5$, $\mathrm{P}=0.000)$. The model $[\mathrm{R} \wedge 2=0.25, \mathrm{~F}(1.93)=31.515$, $P<0.000$ ] explains the $25 \%$ change in the global quality of life. The mean values of CFQoL in patients with insomnia and those with good sleep quality were $53.5 \pm 16.4$ vs. $71.9 \pm 14.9$, respectively $(t=5.613$; $P=0.000)$.

\section{The assessment of the progression of bronchial-pulmo- nary disorders}

The analysis of the spirometry parameter FEV1 showed that in $45.3 \%(n=43)$ of the study group FEV1 was above $70 \%$, suggesting the early stage of the disease. The medium stage of the disease (FEV1 $<70 \%$ and $>40 \%$ ) was diagnosed in $42.1 \%(\mathrm{n}=40)$, and advanced (FEV1 $<40 \%)$ in $12.6 \%(n=12)$ of patients with $\mathrm{CF}$.

There was no significant difference between mean values of FEV1 in the group of patients with the symptoms of insomnia and those with good sleep quality (70.6 \pm 17.8 vs. $66.7 \pm 25.2 ; \mathrm{t}=-0.802 ; P=0.424)$. Only 4 out of 12 patients with advanced bronchial-pulmonary disorders had AIS $\geq 8$ pts.

\section{Pain assessment}

In the past 2 weeks, $42.1 \%(n=40)$ of $C F$ patients experienced pain with the maximum intensity from 2 to 10 pts on the NRS scale. The median pain intensity in patients with insomnia was significantly higher than with good sleep quality ( 7.0 vs. $4.5 ; \mathrm{Z}=-2.746, P=0.005$ ). A moderate positive correlation was found between the pain intensity and sleep quality $(\mathrm{R}=0.45 ; \mathrm{t}=3.075, P=0.003)$

The most common origin of pain was the abdomen $(n=20,55.5 \%)$, head/sinuses $(n=19 ; 52.7 \%)$, chest $(n=15$, $41.7 \%)$, muscles $(n=5 ; 13.9 \%)$, spine $(n=2 ; 5.5 \%)$ and joints $(n=2,5.5 \%)$. Pain located at more than one site was reported by $41.7 \%(n=15)$ of patients.

Table 1. Comparison of patients in terms of demographic and clinical characteristics.

\begin{tabular}{|c|c|c|c|c|}
\hline Parameter & & $\begin{array}{l}\text { Good sleep quality } \\
\qquad(\mathrm{n}=59)\end{array}$ & $\begin{array}{l}\text { Insomnia } \\
(\mathrm{n}=36)\end{array}$ & $P$ \\
\hline \multirow[t]{3}{*}{ Age (years) } & $14-16$ & $19(32.2 \%)$ & $6(16.6 \%)$ & $\chi^{2}=2.783 ; P=0.248$ \\
\hline & $17-20$ & $20(33.9 \%)$ & $15(41.7 \%)$ & \\
\hline & $21-25$ & $20(33.9 \%)$ & $15(41.7 \%)$ & \\
\hline \multirow[t]{2}{*}{ Sex } & Girls & $22(37.3 \%)$ & $19(52.8 \%)$ & $\chi^{2}=1.600 ; P=0.199$ \\
\hline & Boys & $37(62.7 \%)$ & $17(47.2 \%)$ & \\
\hline BMI $\left(\mathrm{kg} / \mathrm{m}^{2}\right)$ & & $19.8 \pm 2.5$ & $19.9 \pm 3.2$ & $t=-0.078 ; P=0.937$ \\
\hline FEV1 (\% of pred.) & & $66.7 \pm 25.2$ & $70,6 \pm 17.8$ & $t=-0.802 ; P=0.424$ \\
\hline \multirow[t]{2}{*}{ Comorbidities * } & No & $29(49.1 \%)$ & $16(40.4 \%)$ & $\chi^{2}=0.198 ; P=0.655$ \\
\hline & Yes & $30(50.8 \%)$ & $20(55.6 \%)$ & \\
\hline
\end{tabular}

Results presented as mean (standard deviation) or numbers (percentages); FEV1 - forced expiratory volume in 1 s; AIS - Athens Insomnia Scale; Good sleep quality - AIS < 8 pts; Insomnia - AIS $\geq 8$ pts.

${ }^{*}$ Comorbidities in cystic fibrosis: pancreatic diseases (exocrine pancreatic insufficiency, $n=66$; diabetes, $n=16$ ), sinus diseases ( $n=14$ ), liver diseases $(n=3)$, bone diseases $(n=5)$, gastrointestinal tract diseases $(n=3)$. 


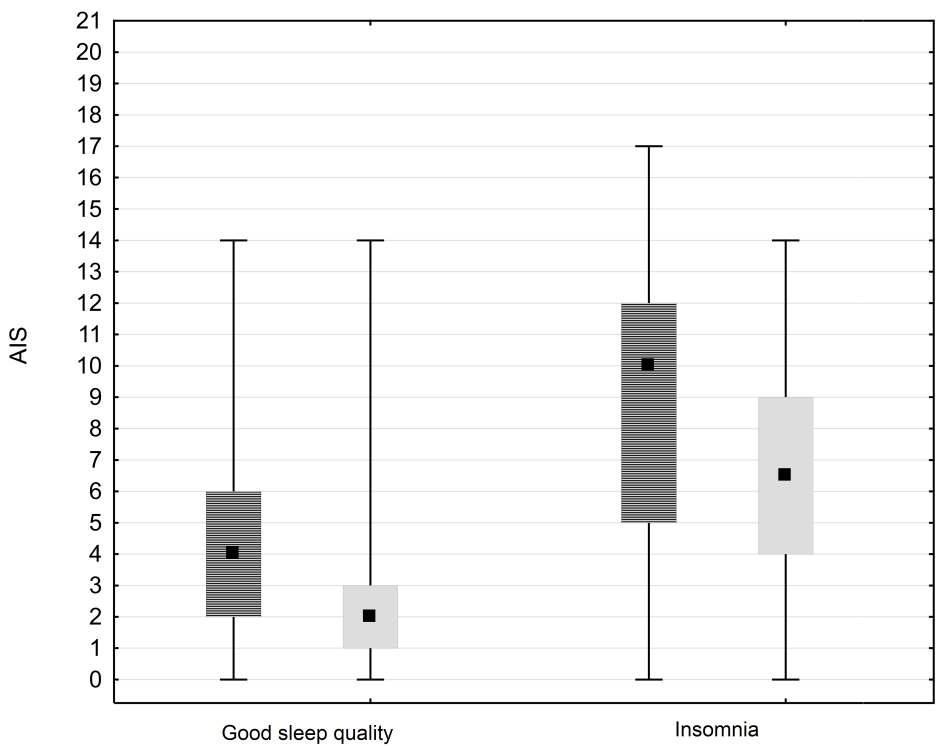

Anxiety: $P=0.000$

Depression: $P=0.000$

Fig. 1. The level of anxiety and depression depending on the quality of sleep. Good sleep quality, $n=59$; Insomnia, $n=36$

In order to eliminate pain the patients most often received temporary $(\mathrm{n}=28 ; 77.8 \%)$ analgesics from the group of non-steroidal anti-inflammatory drugs and/or non-opioids (paracetamol, metamizol). The mean efficacy of the analgesics used in the study was $7.7 \pm 1.8$ on a $0-10$ scale.

\section{The evaluation of anxiety and depression}

Anxiety and "borderline" disorders in patients with CF were diagnosed in $16.8 \%(\mathrm{n}=16)$ and $17.9 \%(\mathrm{n}=17)$, respectively. On the other hand, depressive and "borderline" disorders were diagnosed in $6.3 \%(\mathrm{n}=6)$ and $12.6 \%$ $(n=12)$ of subjects, respectively.

In patients with symptoms of insomnia the level of both anxiety (Me: 10 vs. $4 ; \mathrm{Z}=-4.549 ; P=0.000$ ) and depression (Me: 6.5 vs. $2 ; \mathrm{Z}=-5.534 ; P=0.000$ ) was significantly higher than in the group with good sleep quality (Fig. 1).
The analysis of selected factors determining total AIS score

In order to investigate whether the number of coexisting illnesses, age, gender, FEV1, pain intensity and the level of anxiety and depression are factors affecting total AIS score, linear regression analysis using the stepwise progressive method was performed in patients with CF. Only statistically significant variables, such as depression scores and anxiety scores, were finally introduced into the model. The model proved to be significant $(\mathrm{F} 2.92=$ 32.408; $P<0.000$ ), and all predictors explained a total of $41 \%$ of the dependent variable (Table 2 ).

The logistic regression model indicated that with the aggravation of anxiety and depressive symptoms the risk of insomnia increased 4.3 and 5 times, respectively (Table 3).

Table 2. Predictors of the total AIS score, the results of stepwise progressive regression.

\begin{tabular}{lcccccc}
\hline Predictors & $b^{*}$ & SE of $b^{*}$ & $b$ & SE of $b$ & $t$ & $P$ \\
\hline Depression scores & 0.31 & 0.12 & 0.41 & 0.16 & 2.61 & 0.010 \\
Anxiety scores & 0.37 & 0.12 & 0.42 & 0.13 & 3.11 & 0.002 \\
\hline
\end{tabular}

$\mathrm{b}^{*}$, standardized regression coefficient; $\mathrm{b}$, non-standardized regression coefficient; SE, standard error; $\mathrm{R}^{2}=0.41 ; \mathrm{F}(2.92)=32.408 ; P<0.000 ;$ AIS - Athens Insomnia Scale.

Table 3. Predictors of insomnia, results of logistic regression analysis.

\begin{tabular}{lccc}
\hline Predictors & $B(\mathrm{SE})$ & OR $(95 \% \mathrm{CI})$ & $P$ \\
\hline Level of depression & $1.60(0.50)$ & $4.98(1.84$ to 13.43$)$ & 0.001 \\
Level of anxiety & $1.46(0.34)$ & $4.31(2.20$ to 8.41) & 0.000 \\
\hline
\end{tabular}

$B$, regression coefficient; $\mathrm{CI}$, confidence interval; OR, odds ratio; SE, standard error. Level of depression/anxiety: normal (0-7 pts), borderline (8-10 pts) and clinical levels of symptoms ( $\geq 11 \mathrm{pts})$. 


\section{DISCUSSION}

The quality of sleep is crucial to maintain the wellbeing of a young organism, especially one burdened with CF. Sleep disorders prevent complete recovery of the body, affect many areas of life, induce the development of other diseases, affect the course of the underlying disease, and disturb the next day, as well as promote anxiety and depression ${ }^{29,30}$.

The study results showed that nearly $40 \%$ of patients with CF had sleep disorders in the form of insomnia. This typically resulted in drowsiness during the day. The widespread prevalence of this problem has been observed in paediatric and adolescent patients ${ }^{31}$, as well as in adults with $\mathrm{CF}\left(\right.$ ref. $\left.^{32}\right)$.

Researchers point out that patients with $\mathrm{CF}$ have worse quality of sleep than healthy individuals ${ }^{7,32,33}$. The progression of bronchial-pulmonary disorders and the presence of other comorbidities further lower the quality of sleep in CF patients. Naqvi et al. ${ }^{31}$ described the relationship between the quality of sleep and FEV1 used for monitoring of the progression of bronchial-pulmonary disorders in patients with CF. Like Silva et al. ${ }^{4}$, he observed that hypoxaemia and hypoventilation, which occur during sleep, were not determinants of the quality of sleep. In turn, Vandeleur et al. ${ }^{32}$ reports that some coexisting diseases aggravate sleep disorders.

In addition to evaluating the quality of sleep, medical care in $\mathrm{CF}$ individuals should also include the pain reported by patients. Our study showed in subgroup of patients with pain a link between the quality of sleep and the intensity of pain ${ }^{34,35}$, whose location was heterogeneous. As in the study conducted by Lechtzin et al. ${ }^{36}$, the abdomen and head/sinuses were the sources of pain most often indicated by patients.

Good sleep quality, pain control and psycho-emotional status are important factors determining the patient's wellbeing. It is therefore reasonable to assess the emotional state of CF patients. The results of the study showed that nearly $35 \%$ of the patients were classified as a category: "anxiety" and "borderline" disorders, and about $20 \%$ as a category: "depressive" and "borderline" disorders. It is worth adding that the proportion of patients with depression and anxiety could have been the result of their repressive adaptation. On the other hand, subjective emotions, such as anxiety, depression-like disorders and depression, deteriorate the patient's condition, and thus decrease the quality of sleep. Perhaps, the lesser ability to cope with anxiety and depression in this age group is just one of the many factors that may be responsible for the poor quality of sleep.

It is worth emphasizing that special attention should be paid to the group of patients identified as the "borderline" category, as the transition from "borderline" to "presence of disorder" can be rapid and imperceptible. Such patients ought to be carefully examined in the shortest possible time. It should be noted that HADS is not a tool for diagnosing anxiety, depression, but it merely suggests their presence, and therefore it can be used as a screening tool $^{27,28}$ by various medical professional groups, and not just psychologists. Screening for early diagnosis of depression and anxiety is recommended because of their widespread prevalence and serious health consequences ${ }^{13}$. It is estimated that depression occurs in $6-29 \%$ of children and adolescents, and in $13-33 \%$ of adults ${ }^{16,37,38}$, while anxiety affects $15-30 \%$ of adolescents and $30-38 \%$ of adults with $\mathrm{CF}\left(\right.$ ref. $\left.^{15}\right)$. Depression can be considered as a significant predictor of survival time in patients with CF. Fidika et al. ${ }^{16}$ demonstrated the relationship between depression and FEV1, and this justifies the above conclusions. However, not all reports confirm the existence of such a relationship ${ }^{39}$. It does not change the fact that the detection of anxiety and depression in CF patients (by identifying factors triggering negative emotional states) and the implementation of treatment based on the patient's condition are crucial to ensure well-being. Achieving this goal is possible through proper cooperation between $\mathrm{CF}$ treatment and research centres ${ }^{12,13,16,38,39,40}$.

Negative emotions and sleep disorders disrupt the functioning of the autonomic nervous system, which is associated with a change in response of leukocytes and mediators, and this in turn can adversely affect the course of the disease. The relationship between the immune system and sleep ${ }^{41,42}$, as well as the association with depres$\operatorname{sion}^{43}$, can undoubtedly be regarded as a determinant of cystic fibrosis survival.

The results of our study and those obtained by Bouka et al. ${ }^{7}$ demonstrate that insomnia significantly lowers the quality of life. It is therefore important to quickly diagnose and treat this disorder, both for the comfort of CF patients' life and for socio-economic costs ${ }^{44}$. AIS, which was used in our study, is a good diagnostic tool for insomnia. Its reliability is comparable to the PSQI scale, which is commonly used in CF patients. The similar diagnostic properties of both scales have been confirmed by the meta-analysis performed by Chiu et al. ${ }^{45}$.

\section{Implication for clinical practice}

The analysis of our results and scientific reports indicate the need for a comprehensive, personalized approach to the difficult situation of a young person in the face of an illness and factors destabilizing the condition. Patients treated with care have a chance of reaching up to 50 years of age. It is therefore worth doing our best to improve the detection of predictors that have an impact on the quality of functioning and well-being of the patient.

\section{Study limitations}

The primary limitation of this study is the lack of an objective measure of sleep (e.g. polysomnography) and the evaluation of anxiety and depression using only a screening tool.

A further limitation is the lack of control group, the lack of information how often the subjects reported pain during the day and distinction between acute and chronic pain. 


\section{CONCLUSION}

Insomnia affects a high percentage of CF patients, while anxiety and depression are factors that increase the risk of insomnia. Insomnia reduces the quality of life of CF patients.

Acknowledgement: This work was supported in part by Grants No. 10.10 from the National Tuberculosis and Lung Diseases Research Institute, Poland.

Author contributions: LT: manuscript writing, figures, statistical analysis and interpretation, literature search; GC: study design, manuscript writing, data collection, interpretation, literature search; LP: data collection and data interpretation.

Conflict of interest statement: The authors state that there are no conflicts of interest regarding the publication of this article.

\section{REFERENCES}

1. Sobczyńska-Tomaszewska A, Ołtarzewski M, Czerska K, WertheimTysarowska K, Sands D, Walkowiak J, Bal J, Mazurczak T, NBC CF working group. Newborn screening for cystic fibrosis: Polish 4 years' experience with CFTR sequencing strategy. Euro J Hum Genet 2013;21(4):391-6.

2. Elborm JS. Cystic Fibrosis. Lancet 2016;388:2519-31.

3. Alton EW, Armstrong DK, Ashby D, Bayfield KJ, Biltonet D, Bloomfield EV, Boyd AC, Brand J, Buchan R, Calcedo R, Carvelli P, Chan $\mathrm{M}$, Cheng $\mathrm{SH}$, Collie DD, Cunningham S, Davidson HE, Davies G, Davies JC, Davies LA, Dewar MH, Doherty A, Donovan J, Dwyer NS, Elgmati HI, Featherstone RF, Gavino J, Gea-Sorli S, Geddes DM, Gibson JSR, Gill DR, Greening AP, Griesenbach U, Hansel DM, Harman K, Higgins TE, Hodges SL, Hyde SC, Hyndman L, Innes JA, Jacob J, Jones N, Keogh BF, Limberis MP, Lloyd-Evans P, Maclean AW, Manvell MC, McCormick D, McGovern M, McLachlan G, Meng C, Montero MA, Milligan H, Moyce LJ, Murray GD, Nicholson AG, Osadolor T, Parra-Leiton J, Porteous DJ, Pringle IA, Punch EK, Pytel KM, Quittner AL, Rivellini G, Saunders CJ, Scheule RK, Sheard S, Simmonds NJ, Smith K, Smith SN, Soussi N, Souss S, Spearing EJ, Stevenson BJ, Sumner-Jones SG, Turkkila M, Ureta RP, Waller MD, Wasowicz MY, Wilson JM, Wolstenholme-Hogg P, UK Cystic Fibrosis Gene Therapy Consortium. Repeated nebulisation of non-viral CFTR gene therapy in patients with cystic fibrosis: a randomised, double-blind, placebo-controlled, phase $2 \mathrm{~b}$ trial. Lancet Respir Med 2015;3:684-91.

4. Silva AM, Descalco A, Salgueiro M, Pereira L, Barreto C, Bandeira T, Ferreira T. Respiratory sleep disturbance in children and adolescents with cystic fibrosis. Rev Port Pneumol 2016;22(4):202-8.

5. Jankelowitz L, Reid KJ, Wolfe L, Cullina J, Zee PC, Jain M. Cystic fibrosis patients have poor sleep quality despite normal sleep latency and efficiency. Chest 2005;127:1593-9.

6. Yue HJ, Conrad D, Dimsdale JE. Sleep disruption in cystic fibrosis. Medical Hypotheses 2008;71:886-8.

7. Bouka A, Tiede H, Liebich L, Dumitrascu R, Hecker C, Reichenberger F, Mayer K, Seeger W, Shulz R. Quality of life in clinically stable adult cystic fibrosis out-patients: associations with daytime sleepiness and sleep quality. Respir Med 2012;106:1244-9.

8. Perin C, Fagondes SC, Casarotto FC, Pinotti AF, Menna Barreto SS, Dalcin Pde T. Sleep findings and predictors of sleep desaturation in adult cystic fibrosis patients. Sleep Breath 2012;16:1041-8.

9. de Castro-Silva C, de Bruin V, Cunha GM, Nunes DM, Medeiros CA, de Bruin PF. Melatonin improves sleep and reduces nitrite in the exhaled breath condensate in cystic fibrosis-a randomized, doubleblind placebo-controlled study. J Pineal Res 2010; 48:65-71.

10. Sateia MJ. International Classification of Sleep Disorders - Third Edition. Chest 2014; 146(5):1387-94.
11. Beebe DW. Cognitive, behavioral, and functional consequences of inadequate sleep in children and adolescents. Pediatr Clin North Am 2011;58(3):649-65.

12. Smith BA, Georgiopoulos AM, Quittner AL. Maintaining mental health and function for the long run and cystic fibrosis. Pediatr Pulmonol 2016;51:71-8.

13. Quittner AL, Abbott J, Georgiopoulos AM, Goldbeck L, Smith B, Hempstead SE, Marshal B, Sabadosa K, Elborn S. International Committee on Mental Health in Cystic Fibrosis: Cystic Fibrosis Foundation and European Cystic Fibrosis Society consensus statements for screening and treating depression and anxiety. Thorax 2016;71:26-34.

14. Harning K, Bergsten-Brucefors A, Hjelte L. Depression, anxiety and quality of life in adolescents with cystic fibrosis. J Cyst Fibros 2013;12:130.

15. Oliveira C, Sole A, Girón RM, Quintana-Gallego E, Mondejar $P_{\text {, }}$ Baranda F, Alvarez A, Prados C, Rodríguez-González J, HerreroLabarga I, Quittner A, Olveira G. Depression and anxiety symptoms in Spanish adult patients with cystic fibrosis: associations with health-related quality of life. Gen Hosp Psychiatry 2016;40:39-46.

16. Duff AJ, Abbott J, Cowperthwaite C, Sumner C, Hurley MA, Quittner A, TIDES- Group. Depression and anxiety in adolescents and adults with cystic fibrosis in the UK: A cross-sectional study. J Cyst Fibros 2014;13(6):745-53.

17. Riekert KA, Bartlett SJ, Boyle MP, Krishnan JA, Rand CS. The association between depression, lung function, and health related quality of life among adults with cystic fibrosis. Chest 2007;132:231-7.

18. Fidika A, Herle M, Goldbeck L. Symptoms of depression impact the course of lung function in adolescents and adults with cystic fibrosis. BMC Pulm Med 2014;14:205.

19. Knudsen KB, Pressler T, Mortensen LH, Jarden M, Skov M, Quittner $A L$, Katzenstein T, Boisen KA. Associations between adherence, depressive symptoms and health-related quality of life in young adults with cystic fibrosis. Springer Plus 2016;5(1):1216.

20. Fornal-Pawłowska M, Wołyńczyk-Gmaj D, Szelenberger W. Validation of the Polish version of the Athens Insomnia Scale. Psychiatr Pol 2011; XLV (2):211-21.

21. Soldatos CR, Dikeos DG, Paparrigopoulos TJ. The diagnostic validity of the Athens Insomnia Scale. J Psychosom Res 2003;55:263-7.

22. Yen $C F$, King BH, Chang YP. Factor structure of the Athens Insomnia Scale and its associations with demographic characteristics and depression in adolescents. J Sleep Res 2010;19:12-8.

23. Sands D, Mielus M, Umławska W, Lipowicz A, Oralewska B, Walkowiak J. Evaluation of factors related to bone disease in Polish children and adolescents with cystic fibrosis. Adv Med Sci 2015;60:315-20.

24. Dębska G, Mazurek H. Validation of Polish version of CFQoL in patients with cystic fibrosis. Pol Merkur Lekarski 2007;23(137):340-3.

25. Breivik H, Borchgrevink PC, Allen SM, Rosseland LA, Romundstad L, Hals EK, Kvarstein G, Stubhaug A. Assessment of pain. Br J Anaesth Jul 2008;101(1):17-24.

26. Zigmond AS, Snaith RP. The Hospital Anxiety and Depression Scale. Acta Psychiatr Scand 1983;67:361-70.

27. Borawska-Kowalczyk U, Sands D. Hospital Anxiety and Depression Scale HADS using for healthy and CF adolescents in Poland. Pediatr Pol 2014;89(1)27-32.

28. Brennan C, Worrall-Davies A, McMillan D, Gilbody S, House A. The Hospital Anxiety and Depression Scale: a diagnostic meta-analysis of case-finding ability. J Psychosom Res 2010;69(4):371-8.

29. Katz ES. Cystic fibrosis and sleep. Clin Chest Med 2014:35(3):495-504.

30. Shanahan L, Copeland WE, Angold A, Bondy CL, Costello EJ. Sleep problems predict and are predicted by generalized anxiety/depression and oppositional defiant disorder. J Am Acad Child Adolesc Psychiatry 2014;53(5):550-8.

31. Naqvi SK, Sotelo C, Murry L, Simakajornboon N. Sleep architecture in children and adolescents with cystic fibrosis and the association with severity of lung disease. Sleep Breath 2008;12:77-83.

32. Vandeleur M, Walter LM, Armstrong DS, Robinson P, Nixon GM, Horne RSC. What keeps children with cystic fibrosis awake at night? J Cyst Fibros 2017 May 4. [Epub ahead of print] doi.10.1016/j. jcf.2017.04.012.

33. Jensen JL, Jones CR, Kartsonaki C, Packer KA, Adler FR, Liou TG. Sleep phrase delay in cystic fibrosis: a potential new manifestation of cystic fibrosis transmembrane regulator dysfunction. Chest 2017;152:38693. 
34. Flume PA, Ciolino J, Gray S, Lester MK. Patient-reported pain and impaired sleep quality in adult patients with cystic fibrosis. J Cyst Fibros 2009;8(5):321-5.

35. Sermet-Gaudelus I, de Villartay P, de Dreuzy P, Clairicia M, Vrielynck S, Canoui P, Kirzsenbaum M, Singh-Mali I, Agrario L, Salort M, Charron $B$, Dusser D, Lenoir G, Hubert D. Pain in children and adults with cystic fibrosis: a comparative study. J Pain Symptom Manage 2009;38(2):281-90.

36. Lechtzin N, Allgood S, Hong G, Riekert K, Haythornthwaite JA, Mogayzel P, Hankinson J, Yaster M. The association between pain and clinical outcomes in adolescents with cystic fibrosis. J Pain Symptom Manage 2016;52(5):681-7

37. Smith BA, Modi AC, Quittner AL, Wood BL. Depressive symptoms in children with cystic fibrosis and parents and its effects on adherence to airway clearance. Pediatr Pulmonol 2010;45:756-63.

38. Latchford G, Duff AJ. Screening for depression in a single CF centre. J Cyst Fibros 2013;12:794-6.

39. Casier A, Goubert L, Huse D, Theunis M, Franckx H, Robberecht E, Matthys $\mathrm{D}, \mathrm{Crombez} \mathrm{G}$. The role of acceptance in psychologica functioning in adolescents with cystic fibrosis: A preliminary study acceptance. Psychol Health 2008;23:629-38.
40. Talwalkar JS, Koff JL, Lee HB, Britto CJ, Mulenos AM, Georgiopoulos AM. Cystic Fibrosis Transmembrane Regulator Modulators: Implications for the Management of Depression and Anxiety in Cystic Fibrosis. Psychosomatics 2017;58(4):343-54.

41. Krueger JM, Obál FJ, Fang J, Kubota T, Taishi. The role of cytokines in physiological sleep regulation. Ann NY Acad Sci 2001;933:211-21.

42. Krueger JM, Majde JA. Humoral links between sleep and the immune system: research issues. Ann NY Acad Sci 2003;992:9-20.

43. Fagundes CP, Glaser R, Hwang BS, Malarkey WB, Kiecolt-Glaser JK. Depressive symptoms enhance stress-induced inflammatory responses. Brain Behav Immun 2013;31:172-6.

44. Chevreul K, Michel M, Brigham KB, Lopez-Bastida J, Linertova R Oliva-Moreno J, Serrano-Aguilar P, Posada-de-la-Paz M, Taruscio D, Schieppati A, Iskrov G, Péntek $M$, von der Schulenburg JM, Kanavos P, Persson U, Fattore G. Social/economic costs and health-related quality of life in patients with cystic fibrosis in Europe. Eur J Health Econ 2016;17(Suppl 1):7-18.

45. Chiu HY, Chang LY, Hsieh YJ, Tsai PS. A meta-analysis of diagnostic accuracy of three screening tools for insomnia. J Psychosom Res 2016;87:85-92. 